\title{
BLICKDIAGNOSE-QUIZ-AUFLÖSUNG
}

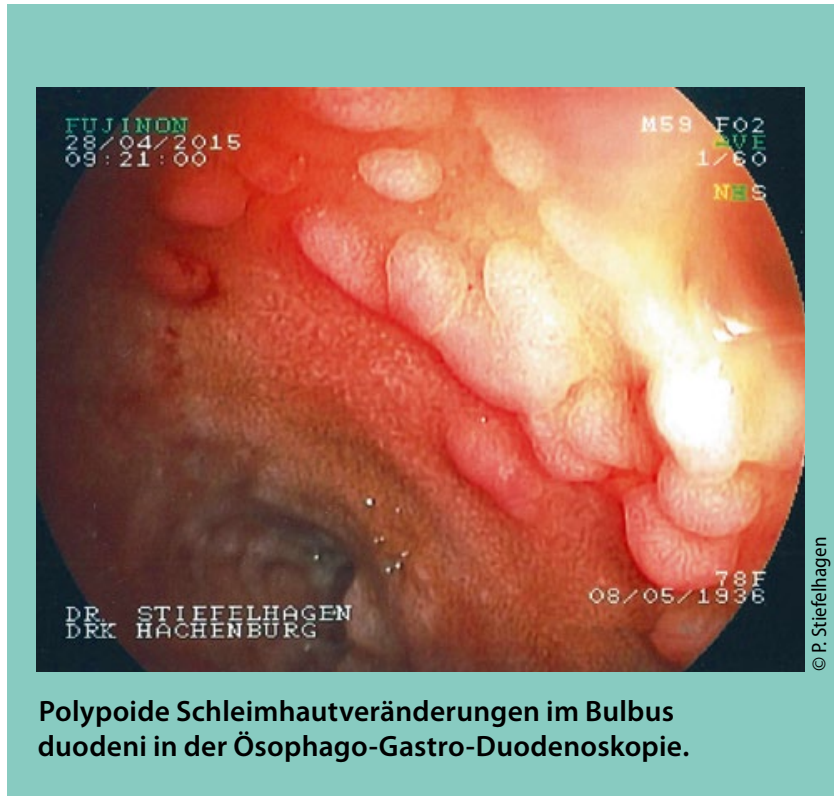

Schleimhautveränderungen

\section{Diese Polypen sind im Grunde harmlos}

\author{
Auflösung von Seite 5.
}

\author{
Richtige Antwort: \\ C) Magenschleimhaut-Heterotopie
}

— Magenschleimhaut-Heterotopien finden sich bei über 10\% aller Endoskopierten. Sie zeigen sich als kleine, bisweilen solitär, meist aber multipel auftretende flache Polypen und sind häufiger an der Vorder- als an der Hinterwand des Bulbus lokalisiert. Oft liegen sie dicht nebeneinander, sodass sie ein pflastersteinartiges Relief bilden. Auch können sie die gesamte Zirkumferenz des Bulbus rasenförmig auskleiden. Ganz selten findet man auch größere, gestielte Heterotopien.

Magenschleimhaut-Heterotopien sind ein harmloser Befund, der keine Beschwerden verursacht und auch keiner Behandlung bedarf. Eine Polypektomie ist also nicht indiziert. Allerdings stellen sie ebenso wie die Schleimhaut im Magen eine Matrix für Magenkarzinome dar. Bei der von dem Patienten beschriebenen Magensymptomatik dürfte es sich um ein funktionelles Krankheitsbild im Sinne einer Non-ulcerDyspepsie handeln.

\section{$\rightarrow$ Dr. med. Peter Stiefelhagen}

DRK-Krankenhaus, Alte Frankfurter Str. 12, D-57627 Hachenburg

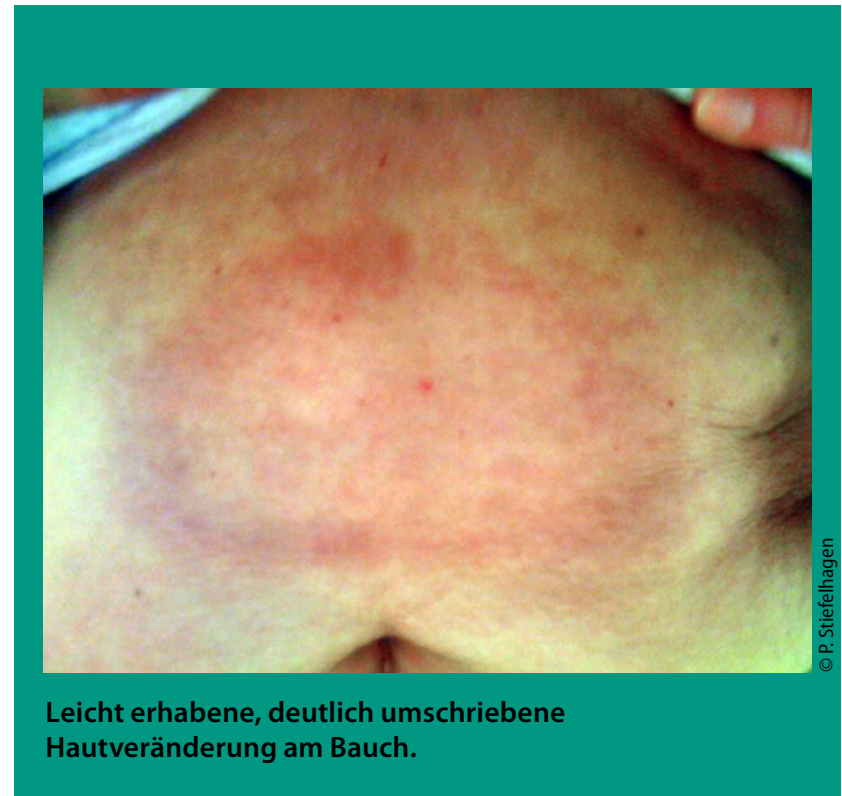

Hautrötung

Klassischer Fall von
Erythema migrans

Auflösung von Seite 5.

Richtige Antwort:

B) Erythema migrans bei Borreliose

Das Erythema migrans, auch Wanderröte genannt, ist die häufigste Manifestation einer Borrelien-Infektion. Es tritt in der Regel 1-2 Wochen nach einem Zeckenstich auf und breitet sich von der Einstichstelle nach peripher aus. Dabei blasst das Zentrum ab, sodass sich ein Ringerythem bildet. Das Zentrum kann sich dabei livide verfärben. Anfangs fehlt die rötliche Randbetonung, sodass das Erythema migrans zunächst oft für einen Insektenstich gehalten wird. Gelegentlich treten auch Allgemeinsymptome wie subfebrile Temperaturen, Kopf- und Gliederschmerzen auf.

Mit der antibiotischen Therapie sollte man nicht auf die Ergebnisse der serologischen Untersuchung warten, da in über $50 \%$ der Fälle beim Auftreten der Wanderröte noch keine Antikörper nachweisbar sind. Unbehandelt kommt es bei ca. 75\% der Infizierten zu einer artikulären, kardialen, kutanen oder zentralnervösen Manifestation. Als Antibiotikum kommen in Frage: $2 \times 100 \mathrm{mg} / \mathrm{d}$ Doxycyclin, $3-4 \times 500-750 \mathrm{mg} / \mathrm{d}$ Amoxicillin, $2 \times 500 \mathrm{mg} / \mathrm{d}$ Cefuroxim, jeweils über drei Wochen, oder $2 \times 250 \mathrm{mg} / \mathrm{d}$ Azithromycin über zehn Tage. 